\title{
Factors associated with non-attendance in a general practice super clinic population in regional Australia: A retrospective cohort study
}

\author{
Susan Nancarrow, Joanne Bradbury, Catherine Avila
}

School of Health and Human Sciences, Southern Cross University, Lismore, Australia

\section{RESEARCH}

Please cite this paper as: Nancarrow SA, Bradbury J, Avila C. Factors associated with non-attendance in a general practice super clinic population in regional Australia: A retrospective cohort study. AMJ 2014, 7, 8, 323-333. http://doi.org/10.21767/AMJ.2014.2098

Corresponding Author:

Prof Susan Nancarrow

School of Health and Human Sciences

Southern Cross University

PO BOX 157, Lismore, NSW 2480

Australia

Email: susan.nancarrow@scu.edu.au

\section{ABSTRACT}

\section{Background}

Non-attendance at medical appointments is associated with increased patient morbidity and is a significant drain on health service resources. Australian studies have focused on secondary healthcare settings, screening, and interventions to reduce non-attendance.

\section{Aims}

To explore factors associated with non-attendance in a regional primary care setting.

\section{Method}

A retrospective cohort of all patients with a scheduled appointment between October 2011 and October 2013 at a regional, primary care clinic providing medical and allied health services in a region of New South Wales (NSW) serving a large Aboriginal population (10.7 per cent). Using multivariate logistic regression, non-attendance was regressed on a range of covariates, including number of appointments per person, gender and ethnicity, and day of the week.

\section{Results}

The overall proportion of missed appointments was 7.6 per cent. Risk factors for non-attendance were day of the week [Mondays (8.1 per cent), Fridays (8.0 per cent), and Thursdays (7.9 per cent), $(\chi 2(4)=20.208, p<0.0005]$, having fewer scheduled appointments [ $\leq 5$ appointments resulted in 19.1 per cent greater risk of failure to attend (FTA) $(95 \%$ $\mathrm{Cl}: 11-28 \%)] ;$ Aboriginality (OR=4.022, 95\% Cl: 3.263, 4.956), and female gender (OR=1.077; 95\% Cl 1.024, 1.132). There was a trend toward an interaction between gender and Aboriginality, with Aboriginal females being the group most likely to miss appointments (OR=1.272, 95\% Cl: $0.949,1.705)$.

\section{Conclusion}

This is the largest study of non-attendance in an Australian primary healthcare setting. While not a typical setting, the study had the advantage of a large, mixed population. The suggested high rates of non-attendance by Aboriginal females have potentially important policy implications.

\section{Key Words}

Non-attendance, super clinic, Aboriginal

\section{What this study adds:}

\section{What is known about this subject?}

Non-attendance at medical appointments is associated with increased patient morbidity and is a significant drain on health service resources; however, studies investigating who is most at risk, in an Australian primary healthcare setting, are lacking.

\section{What new information is offered in this study?}

Indigenous Australians are three times more likely to miss a scheduled medical appointment than non-Indigenous Australians at this regional clinic, and Aboriginal women may be at the highest risk of missing appointments.

\section{What are the implications for research, policy, or practice?}

Given the central role of women in family health, the identification of high rates of non-attendance by Aboriginal females requires further elucidation that could have important policy implications. 


\section{Background}

Non-attendance at medical appointments is associated with increased patient morbidity ${ }^{1}$ and is a drain on health service resources resulting in service inefficiencies. For instance, missed outpatient appointments were estimated to cost the United Kingdom health system $f 585 \mathrm{~m}$ in $2012 .^{2}$ Studies in primary and secondary healthcare settings in Europe, North and Latin America, Australia, and Asia report non-attendance rates of between $6.5-43 \% .^{3-6}$ Notably, there is limited data about the rates of non-attendance and its economic consequences in primary healthcare settings in Australia.

The Australian studies that explore non-attendance focus on secondary healthcare settings, ${ }^{7,8}$ screening services, ${ }^{9}$ and interventions to reduce non-attendance. ${ }^{10,11}$ However, without an understanding of those most at risk of nonattendance, it is difficult to design appropriately targeted interventions to reduce non-attendance.

A recent systematic review and evidence synthesis on the effectiveness of different reminder systems in outpatient settings ${ }^{12}$ found that few studies had investigated the effect of patient attributes on appointment behaviour (attendance, cancellation, or rebooking). However, age was consistently reported as a risk factor for non-attendance, with younger adults more likely to be non-attenders than older patients. ${ }^{13-17}$ The patterns of attendance for children (under 18 years) were less consistent, lacked data, and were derived from a range of different settings. The effect of gender on attendance was also unclear; however, there appears to be a dominant belief that males are less likely to attend appointments than females. A small number of studies have reported higher rates of non-attendance by girls ${ }^{18}$ and women, ${ }^{16}$ one suggesting that childrearing responsibilities play a part in non-attendance. ${ }^{19}$ Deprivation is consistently associated with nonattendance; however, the evidence is weak. ${ }^{18,20}$ Importantly, only one study reported that younger, unmarried women of lower socioeconomic status were less likely to attend than more affluent patients. ${ }^{21}$

The relationship between ethnicity and attendance is inconsistent. One Australian study of non-attendance at second-round mammographic screening found that those at risk for non-attendance were women from a non-English speaking background ( $R R=1.18-1.77)$ and Indigenous women ( $R R=2.02,95 \% \mathrm{Cl}: 1.61-2.54)$. The same study found that women from rural and remote locations were less likely to miss their appointment; however, symptomatic women were less likely to attend.

\section{Study context}

This research was undertaken in a privately operated healthcare clinic in Northern New South Wales, where reminder phone calls 24 hours prior to an appointment are standard protocol. ${ }^{22}$ This practice specialises in providing primary healthcare to Indigenous Australians. It uses a unique approach based on social entrepreneurship ${ }^{23}$ and incorporating Medicare incentives to create an innovative model of affordable, accessible care for the local Indigenous community. This model presents a private sector alternative to the Aboriginal Controlled Community Health Organisations (ACCHOs). ${ }^{24}$

Lismore is a regional hub, located in Northeastern New South Wales, Australia. Lismore Central and the surrounding area has a population of around 45,000 people, of whom 1,579 (0.035 per cent) identify as Aboriginal or Torres Strait Islander. ${ }^{25}$ Hereafter the local Aboriginal and Torres Strait Islander community will be referred to as Aboriginal, as this is the preferred term.

The Aboriginal population of Lismore is relatively young, with half the population (50.1 per cent, $n=791$ ) being aged 19 years and under, compared with 27.4 per cent of the non-Aboriginal population. Only 2 per cent of the Aboriginal population is aged 65 years and over, (7.1 per cent of the non-Aboriginal population).

The health status of the Lismore population as a whole is below that of the rest of the state with higher rates of chronic disease risk factors than for NSW as a whole; and avoidable mortality for both intentional and unintentional injuries. ${ }^{26}$ However, Aboriginal health is worse than the state average for both the Aboriginal and non-Aboriginal people for many conditions. Between 2002-05, hospitalisation rates for Aboriginal people in the Northern NSW Local Health District (NNSWLHD) was 20 per cent higher than the rate for all Aboriginal people in NSW. Hospitalisation rates for cardiovascular disease amongst Aboriginal people in the NNSWLHD were 24 per cent higher than the NSW average. Other areas of excess risk include diabetes and low birth weight babies. ${ }^{26,27}$

\section{Method}

\section{Participants, setting and design}

A retrospective cohort of all patients who had scheduled an appointment at the clinic between 24 October 2011 and 22 October 2013 was included in the analysis. The community-based clinic (hereafter called "the clinic") comprises a community-based medical and allied healthcare service delivery in an attempt to be a "one-stop shop" for most community healthcare needs. The clinic is 
located in a suburb with a disproportionately high proportion of Indigenous peoples (10.7 per cent) compared with neighbouring areas (Lismore; 3.5 per cent) and the national Australian average ( 2.3 per cent). ${ }^{28}$

\section{Outcome measurement and data analysis}

Failure to attend (FTA) per appointment was documented in a live database. Attendance was the primary outcome for this analysis with each scheduled appointment denoted as either attended (0) or not attended (1). This was a secondary data analysis as the primary reason the data were collected was as part of routine operations of the clinic. The basic appointment schedule was for a 15-minute consultation with a medical practitioner. A second appointment for the same day was scheduled when a longer consult, test, or referral to an allied practitioner is required (e.g., blood test or appointment with chronic care nurse). Each appointment scheduled was recorded separately and thereby analysed independently.

Using multivariate logistic regression, FTA was regressed on a range of covariates, such as number of appointments per person, sex and self-defined ethnicity of person making the appointment, and the day of the week on which the appointment was scheduled.

The data was analysed in two ways. First, the scheduled appointment was used as the unit of analysis to assess the proportion of scheduled appointments that were not attended to total visits and explore the relative impact of demographic characteristics using multivariate logistic regression. Demographic characteristics evaluated were sex, nationality, postcode, day of the week, and age. Second, individual patients were used as the unit of analysis to assess for interactions and relative effect sizes using analysis of variance (ANOVA) with the mean number of FTA per person calculated and used as an outcome. Characteristics to assess for significance and effect size included sex, age, and nationality.

Data was analysed using IBM SPSS v20. Minimum probability levels were set at 5 per cent for hypothesis testing and 1 per cent for assumption testing. Where test assumptions were not met, non-parametric tests would be used and if consistent, the parametric findings would be reported for ease of interpretation. Chi-square analyses were used in cross tabulations on categorical data. Ethics approval was obtained from the Southern Cross University Ethics Committee (ECN-13-054).

\section{Results \\ Preliminary statistics}

There were 90,901 appointments scheduled by 8,634 individuals over the two-year period. The number of appointments per person ranged from 1-178, with a mean $[(\mathrm{M})=10.76, \mathrm{SD}=14.5]$

This was a positively skewed distribution (median $=5$ ) with half the sample booking five or less appointments during the two-year period, and 25 per cent scheduling two or less, while 25 per cent scheduled more than 13 appointments. To control for multiple appointments per person, a dummy variable for number of appointments was created around the median $(0 \leq 5 ; 1>5)$; that is, multiple appointments as indicated by whether a person had more than one appointment over the two-year period. Whether these appointments were on the same or different days could not be determined by these data as this information was not available.

Females accounted for the larger proportion of scheduled appointments (53.3 per cent). Ages ranged from zero (babies who had not yet had their first birthday) to 94 years. The proportion of scheduled appointments for children ( $\leq 16$ years) was 15.1 per cent, while 25 per cent of appointments were for children and young people 18 years or younger. The median age for all appointments was 43 years. Most of the appointments were made by people residing within the local postcode address 82,727 (89 per cent).

A range of ethnicities were self-identified by clinic patients. By far the greatest proportion of visits were made by nonAboriginal Australians 61,442 (66.1 per cent), followed by Aboriginal Australians 25,236 (27.1 per cent), and a third category comprising a broad range of nationalities collectively labelled "Other" 6,323 (6.8 per cent) for the purpose of this analysis.

The proportion of FTA to total scheduled appointments for the two-year period was 7.5 per cent $(6,934)$, with 90.3 per cent $(83,851)$ attending and 2.3 per cent $(2,116)$ pending; thus it was unknown whether these appointments were attended at the time that the data were downloaded from the live database. Cases with "unknown" FTA data were therefore excluded from the analysis, resulting in a slightly reduced dataset comprising $n=90,785$ appointments from 24 October 2011 to 22 October 2013, an FTA prevalence of 7.6 per cent and attendance rate of 92.4 per cent per overall number of scheduled appointments. 
To assess whether day of week was a covariate for FTA categories, a cross-tabulation analysis was conducted, and a chi-square test found a significant effect $(\chi 2(4)=20.208$, $p<0.0005)$. Mondays (8.1 per cent), Fridays (8.0 per cent), and Thursdays (7.9 per cent) had higher than expected FTA occurrences, while Tuesdays and Wednesdays (both 7.2 per cent) had lower than expected FTA occurrences. As there was such a distinct difference between the three high FTA days and the two low FTA days, this variable, day of week, was recoded into an indicator variable using Monday, Thursday, and Friday as high FTA, and Tuesday and Wednesday as low FTA occurrence days.

The average weekly FTA occurrence rates for nonIndigenous Australians was similar to that of the "Other" nationality category (4.8 per cent and 4.7 per cent, respectively), while that for Indigenous Australians was around three times higher (15.4 per cent).

\section{Predictors of failure to attend}

To estimate the adjusted effects of day of the week, local postcode, sex, age, and ethnicity on FTA occurrences, a multivariate logistic regression model was fit to the data. The model fit chi-square $(\chi 2(6)=3264.49, p<0.0005)$ was significant indicating the suitability of the model compared with the null model (no covariates). The Cox \& Snell (0.037) and Nagelkerke (0.088) R-squares indicate that the model explains 3.5-8.5 per cent of the variance in FTA.

The model (Table 1 ) indicates that all our covariates are significant predictors of the likelihood a scheduled appointment will result in a FTA occurrence. The number of appointments was inversely related to the likelihood of FTA; that is, appointments scheduled by those with fewer (5 or less) appointments over the two-year period were around 19.1 per cent (95\% Cl: 11-28\%) more likely to result in a FTA occurrence.

Age was also inversely related to FTA; for each additional year of age associated with the appointment holder, there was a 1.5 per cent reduction in the likelihood the appointment will result in FTA. Appointments scheduled by females were 6.3 per cent more likely to result in FTA, but the confidence interval is wide, suggesting the true estimate could be anywhere between 1.1-11.9 per cent. The odds that a scheduled appointment resulted in an FTA occurrence were three times higher in Indigenous Australians than others, including non-Indigenous Australians, in the cohort.
The predictive model that could be applied to an appointment to estimate the likelihood that the appointment will result in a FTA occurrence is as follows:

$Z($ FTA $)=$ $-2.427-0.176(\mathrm{NAppt})+0.89(\mathrm{DayOf} W \mathrm{~K})+$ $0.131($ PCode $)-0.015$ (Age) +1.101 (Aborig)

Probablity $($ FTA $)=\frac{e^{x}}{1+e^{x}}$

\section{Exploring group effects}

There were $n=8,544$ unique clients/patients in the data. The breakdown of sex and Aboriginality on age is given in Table 2 . The Aboriginal males were 13 years younger and females were 10 years younger than the non-Aboriginal cohort.

To compare groups, a mean score for number of FTA occurrences per person was computed and used as a continuous outcome variable. The distribution of mean FTA was not normal, with most of the observations having a zero score. Therefore, mean FTA was not used as an outcome in an ANOVA, but the binary FTA occurrence was used in a logistical regression model (Table 3 ).

To explore group effect, the study population was categorised into subgroups based on sex, Aboriginality, and adults/children (Figure 1) and analysed for mean FTA. Comparison of the means suggested that FTA was lower for children in both Aboriginal and non-Aboriginal groups, but that Aboriginal children were much more likely to FTA than non-Indigenous children or non-Indigenous adults. Female Aboriginal adults had the highest mean FTA occurrence of all subgroups (Table 2 and Figure 1), while female nonAboriginal children had the lowest mean FTA. Caution was taken in interpreting these data as the outcome was nonnormally distributed. However, these findings were consistent with those from the logistic model (Table 3).

Figure 1: Mean FTA occurrence per person $(n=8,544)$ by demographic subgroups in a regional clinic between October 2011 and October 2013

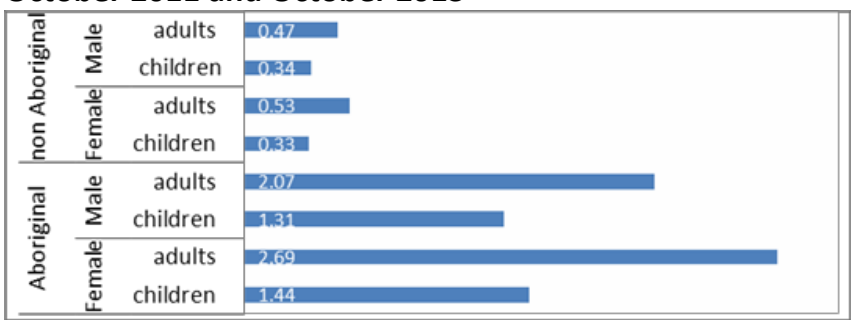


A dummy interaction variable was created from the cross product between sex and Aboriginality, such that $1=$ female and Aboriginal and $0=$ not female and Aboriginal. Interestingly, when this cross product was modelled in the full logistic regression of number of scheduled appointments on covariates (Table 4), there was a small effect size with a wide confidence interval that crossed the null and was therefore non-significant. However, the effect size for the sex variable in the model was reduced substantially to the point that it was no longer significant and it was indeed even lower than the effect size of the interaction term, suggesting that the interaction term may have accounted for most of the variance in sex in the original model. Therefore, while not significant, the effect size suggests that the interaction between sex and Aboriginal nationality was more important than sex alone for predicting the likelihood of FTA per scheduled appointment.

When the units of analysis were individual clients (rather than appointment occasions), and the effects of children and adults were separated (Table 3 ), it is of note that Aboriginality was the only significant predictive factor for FTA in children and young people and that Aboriginal children and young people were 2.9 times more likely than non-Aboriginal children to FTA. For the adult cohort, there was a negative effect for age, such that as patients get older there is a reduced risk of FTA. The likelihood of nonattendance by an Aboriginal adult was four times higher than for a non-Aboriginal adult, with the $95 \% \mathrm{Cl}$ suggesting that this could be as high as five times higher (4.956). Sex was not a variable of impact, but in adults Aboriginal females were bordering significance for inclusion in the model at the $p=0.1$ level. The OR for Aboriginal females was 1.27 (95\% Cl: 0.95-1.75), which suggests that the effect size is 27 per cent higher for this group as a whole (compared with all males and non-Aboriginal females), but there is wide variation within Aboriginal females; that is, there could be a subgroup of Aboriginal females that are leveraging the FTA.

This study has identified significant predictors of the likelihood of a scheduled appointment at a regional general practice super clinic resulting in non-attendance. The single most significant factor predicting non-attendance was selfreported Australian Aboriginal or Torres Strait Islander nationality $(\mathrm{OR}=3.00,95 \% \mathrm{Cl}: 2.85-3.17)$. Sex was also a significant factor, with appointments scheduled for females more likely to be missed than males. However, the effect size for sex fell dramatically and significantly when an interaction term between sex and Aboriginality was introduced to the model ( $\mathrm{OR}=1.080,95 \% \mathrm{Cl}$ : 0.976-1.96).
Despite the interaction term being not significant, there was a trend towards a higher likelihood that an appointment scheduled by a female Aboriginal adult would be more likely to result in non-attendance. These subtle data trends are very interesting and worthy of further exploration. Aboriginal children were much more likely to miss their appointment than non-Aboriginal children or non-Aboriginal adults. Indeed, in the child cohort, the only significant predictor of whether a child ( $<=16$ years) missed a scheduled appointment was Aboriginality. This medical clinic is not in a remote part of Australia, but part of a regional community along the eastern seaboard, where many Australians reside.

\section{Discussion}

Surprisingly, little research has been undertaken into reasons for non-attendance in primary healthcare clinics in Australia, and to our knowledge, this is the largest published Australian study on primary care non-attendance and the first to document the extent of non-attendance by Australian Aboriginal patients in primary care.

The study reinforces previous research findings that younger patients are less likely to attend than older patients. However, the high rate of non-attendance by younger Aboriginal women and children has not been reported elsewhere. The overall younger age of the Aboriginal population may be attributed to the younger age of Aboriginal people overall compared with nonAboriginal people. However, the gender disparity is less easy to explain, but is worthy of exploratory, qualitative analysis to try to identify possible reasons and drivers for missing scheduled medical appointments.

The findings are particularly important in the local context. Forty-eight per cent of Aboriginal women in the NNSWHLD smoke during pregnancy, in comparison with 15 per cent in the non-Aboriginal population. In addition, the pre-term birth rate is 9.4 per cent in the Aboriginal population compared with 6.1 per cent in the non-Aboriginal population. Pre-term birth and low birth weight are the leading causes of neonatal and infant mortality, ${ }^{29}$ a major cause of short and long-term morbidity ${ }^{30-32}$, and is extremely costly to the health system. ${ }^{31}$ Therefore, preventative interventions that target younger Aboriginal women to positively affect their own health, as well as their reproductive and maternal health, have enormous potential to benefit the whole community. ${ }^{33-34}$

\section{Limitations}

This study relied on retrospective, routinely collected appointment data from the clinic database. Data was 
collected and recorded by medical secretaries and not by experienced researchers and information on nationality was based on self-reported data by the patient. The data analyses were secondary to the reasons for the data collection and therefore the findings should be considered exploratory in nature. Indeed, some may argue that these are "real world data" and are therefore more valid than data collected for research and analysis.

Nevertheless, more analytic questions and solid conclusions would have involved having more control over the types of data that were included in the data collection. As it was, the data comprised the entire population of a regional health clinic, with over 90,000 observations. Certainly, these data had sufficient potential to describe interesting data trends worthy of following up in future, more targeted research. More specifically, we were unable to capture the impact of other likely risk factors on attendance, such as diagnoses and comorbidities. This information may have helped to explain why people with more appointments, most likely with chronic diseases, were less likely to miss appointments. The amount of explained variance (R-squared) by the covariates on the outcome was less than 10 per cent, indicating that there were other factors missing from the model, which could explain more of the variance in the outcome.

It would also have been interesting to note the structure of the appointment; for instance, whether it was a double appointment or linked to an allied health appointment, which may have been entered as two appointments on the same day. This information was not available to the research team.

In addition, the information about how many appointments were double appointments or at least scheduled for the same day was not available. This has the potential to bias our estimate of FTA rates. For instance, if people who fail to attend are those with multiple appointments on the same day, the non-attendance estimate will be inflated. However, it is also possible that those with multiple appointments were on chronic care plans and may be less likely to FTA, which would underestimate our prevalence of non-attendance. Future research in this area should attempt to control for the quite complex scheduling structure associated with medical databases.

In the current study, the effects of these data limitations, particularly the potential violation of the assumption of independence, were addressed by including a second data analysis using participants as the unit of analysis. In this second analysis, there was no violation to the assumption of independence, and the results were fairly consistent with those of our primary data analysis. Indeed, the results from the second data analysis demonstrated slightly higher OR for Aboriginality, indicating that the effect of the data limitation (uncontrolled multiple appointment structure) was most likely to bias the OR towards underestimation, which is a preferred bias as it is more rigorous than an overestimation.

The clinic is relatively unusual in that it serves a very large Aboriginal population, but is not an Aboriginal Medical Service. This provided us with the unusual analytical advantage of comparison between different population groups; however, it may limit the generalisability of the findings to other contexts. This study was initially motivated by an economic imperative to identify ways to reduce non-attendance. This was to support the business model that enables bulk billing of patients so that care can be delivered free at the point of access. Appointment nonattendance substantially reduces service efficiency, and therefore the sustainability of this business model. While it is well accepted, anecdotally at least, that Aboriginal patients are at high risk of non-attendance at appointments, this has not been quantified previously.

\section{Conclusion}

This analysis has demonstrated that Indigenous Australians are three times more likely to miss a scheduled medical appointment than non-Indigenous Australians and people from other nationalities residing in a regional (not remote) community along the busy Australian seaboard. It has also uncovered surprising, subtle data trends suggesting that Aboriginal women may be at the highest risk of missing appointments and that Indigenous children are more likely to miss an appointment than non-Indigenous children and non-Indigenous adults. The reasons and drivers of these risk factors need to be further explored through qualitative research designs in the Aboriginal community. There is acknowledgment at the highest level of government in Australia of the need to "close the gap" between Indigenous and non-Indigenous health care. This study identifies a need for policies that specifically target Aboriginal women and helps overcome barriers to attendance at health services.

\section{References}

1. Krishna M, Amarjothi S. Reminder letters to improve rate of attendance at Community Mental Health Centre. BJMP 2012;5(1):a502. Available from: http://www.bjmp.org/files/2012-5-1/bjmp-2012-5-1a502.pdf. 
2. Dr Foster Limited. (2012). Is your hospital fit for the future: Dr Foster hospital guide 2012. [cited 2014 July 1]. Available from: http://download.drfosterintelligence.co.uk/Hospital_G uide_2012.pdf.

3. Waller J, Hodgkin P. Defaulters in general practice: Who are they and what can be done about them? Fam Pract. 2000 Jun;17(3):252-3.

4. Cashman S, Savageau J, Lemay C, Ferguson W. Patient Health Status and Appointment Keeping in an Urban Community Health Center. J Health Care Poor Underserved. 2004 Aug;15(3):474-88.

5. Giunta D, Briatore A, Baum A, Luna D, Waisman G, de Quiros FG. Factors associated with nonattendance at clinical medicine scheduled outpatient appointments in a university general hospital. Patient Prefer Adherence. 2013 Nov 8;7:1163-70. doi: 10.2147/PPA.S51841.

6. Zailinawati A, Ng C, Nik-Sherina H. Why do patients with chronic illnesses fail to keep their appointments? A telephone interview. Asia Pac J Public Health. 2006;18(1):10-5.

7. Farley RL, Wade TD, Birchmore L. Factors influencing attendance at cardiac rehabilitation among coronary heart disease patients. Eur J Cardiovasc Nurs. 2003 Sep;2(3):205-12.

8. Worcester MU, Murphy BM, Mee VK, Roberts SB, Goble AJ. Cardiac rehabilitation programmes: predictors of non-attendance and drop-out. Eur J Cardiovasc Prev Rehabil. 2004 Aug;11(4):328-35.

9. O'Byrne A, Kavanagh AM, Ugoni A, Diver F. Predictors of non-attendance for second round mammography in an Australian mammographic screening programme. J Med Screen. 2000;7(4):190-4.

10. Downer SR, Meara JG, Da Costa AC. Use of SMS text messaging to improve outpatient attendance. Med J Aust. 2005 Oct 3;183(7):366-8.

11. Taylor NF, Bottrell J, Lawler K, Benjamin D. Mobile telephone short message service reminders can reduce nonattendance in physical therapy outpatient clinics: a randomized controlled trial. Arch Phys Med Rehabil. 2012 Jan;93(1):21-6. doi: 10.1016/j.apmr.2011.08.007.

12. McLean S, Gee M, Booth A, Salway S, Nancarrow S, Cobb M, et al. TURNUP: Targeting the Use of Reminders \& Notifications for Uptake by Populations. London: National Institute of Health Research 2014.

13. Hamilton W, Round A, Sharp D. Patient, hospital, and general practitioner characteristics associated with non-attendance: a cohort study. Br J Gen Pract. 2002 Apr;52(477):317-9.

14. Parikh A, Gupta K, Wilson AC, Fields K, Cosgrove NM, Kostis JB. The effectiveness of outpatient appointment reminder systems in reducing no-show rates. Am J Med. 2010 Jun;123(6):542-8. doi: 10.1016/j.amjmed.2009.11.022.

15. Booth PG, Bennett HE. Factors associated with attendance for first appointments at an alcohol clinic and the effects of telephone prompting J Subst Use 2004;9:269-79.

16. Waller J, Hodgkin P. Defaulters in general practice: who are they and what can be done about them? Fam Pract. 2000 Jun;17(3):252-3.

17. Moore CG, Wilson-Witherspoon P, Probst JC. Time and money: effects of no-shows at a family practice residency clinic. Fam Med. 2001 Jul-Aug;33(7):522-7.

18. Can S, Macfarlane T, O'Brien K. The use of postal reminders to reduce non-attendance at an orthodontic clinic: a randomised controlled trial. Br Dent J. 2003 Aug 23;195(4):199-201; discussion 196.

19. Cohen AD, Kaplan DM, Kraus M, Rubinshtein E, Vardy DA. Nonattendance of adult otolaryngology patients for scheduled appointments. J Laryngol Otol. 2007 Mar;121(3):258-61. Epub 2006 Oct 20.

20. Sharp DJ, Hamilton W. Non-attendance at general practices and outpatient clinics: Local systems are needed to address local problems. BMJ. 2001 Nov 10;323(7321):1081-2.

21. Oladipo A, Ogden S, Pugh S. Preclinic appointment telephone contact: an effective intervention for colposcopy clinic nonattendance. J Low Genit Tract Dis. 2007 Jan;11(1):35-8.

22. Akter S, Doran F, Avila C, Nancarrow S. A qualitative study of staff perspectives of patient non-attendance in a regional primary healthcare setting. Australas Med J. 2014 May 31;7(5):218-26. doi: 10.4066/AMJ.2014.2056. eCollection 2014.

23. Tedmanson D, Guerin P. Enterprising social wellbeing: social entrepreneurial and strengths based approaches to mental health and wellbeing in "remote" Indigenous community contexts. Australas Psychiatry. 2011 Jul;19 Suppl 1:S30-3. doi: 10.3109/10398562.2011.583078.

24. Fredericks B, Legge D. Revitalizing Health for All: International Indigenous Representative Group Learning from the Experience of Comprehensive Primary Health Care in Aboriginal Australia-A Commentary on Three Project Reports. The Lowitija Institute, 2011. (accessed 2014 July 1) Available from: https://www.lowitja.org.au/sites/default/files/docs/Re vitalising_Health_report.pdf.

25. Public Health Information Development Unit (PHIDU). Social Health Atlas of Australia: Medicare Local (online). (accessed 2014 July 1) Available from: http://www.adelaide.edu.au/phidu/maps-data/data/

26. NSW Government. Health Statistics NSW 2012. 
(accessed 2014 July 1) Available from: http://www.health.nsw.gov.au/publichealth/hsnsw/in dex.asp.

27. Australian Institute of Health and Welfare. Aboriginal and Torres Strait Islander Health Performance Framework 2010. AlHW; 2010. p. 2140. (accessed 2014 July 1) Available from: www.aihw.gov.au/publicationdetail/?id=10737420099.

28. Australian Bureau of Statistics. Research and experimental development, higher education organisations, Australia, 2010, (Catalogue No. 8111.0). (accessed 2014 July 1) Available from http://www.abs.gov.au/ausstats/abs@.nsf/mf/8111.0.

29. Lawn JE, Gravett, MG. Nunes, TM. Rubens, CE. Stanton, C. and the GAPPS Review Group. Global report on preterm birth and stillbirth (1 of 7): definitions, description of the burden and opportunities to improve data. BMC Pregnancy Childbirth. 2010 Feb 23;10 Suppl 1:S1. doi: 10.1186/1471-2393-10-S1-S1.

30. Saigal S, Doyle, L W. Preterm birth 3: An overview of mortality and sequelae of preterm birth from infancy to adulthood. Lancet. 2008 Jan 19;371(9608):261-9. doi: 10.1016/S0140-6736(08)60136-1. Review.

31. Behrman RE. Butler AS (editors). Causes consequences and prevention committee on understanding premature birth and assuring healthy outcomes. Washington D.C.: National Academies Press (US); 2007.

32. Hack M, Klein NK, Taylor HG. Long-term developmental outcomes of low birth weight infants. Future Child. 1995 Spring;5(1):176-96.

33. Panaretto $K$, Lee $H$, Mitchell $M$, Larkins $S$, Manessis $V$, Buettner $P$, Watson $D$. Risk factors for preterm, low birth weight and small for gestational age birth in urban Aboriginal and Torres Strait Islander women in Townsville. Aust N Z J Public Health. 2006 Apr;30(2):163-70.

34. Moore HC, Klerk Nd, Richmond P, Lehmann D. A retrospective population-based cohort study identifying target areas for prevention of acute lower respiratory infections in children. BMC Public Health. 2010 Dec 7;10:757. doi: 10.1186/1471-2458-10-757.

\section{ACKNOWLEDGEMENTS}

Grateful thanks to the management and staff of the Lismore General Practice Super Clinic, particularly Mr John Brice and Ms Terese Forzan for facilitating access to the relevant material.

\section{PEER REVIEW}

Not commissioned. Externally peer reviewed.

\section{CONFLICTS OF INTEREST}

The authors declare that they have no competing interests.

\section{ETHICS COMMITTEE APPROVAL}

Ethics approval was obtained from the Southern Cross University Ethics Committee (ECN-13-054). 
Table 1. Multivariate logistical regression model predicting likelihood of FTA occurrence per scheduled appointment ( $n=90,758$ appointments between $2011-2013$ at community medical centre)

\begin{tabular}{|c|c|c|c|c|c|c|c|c|}
\hline \multirow[t]{2}{*}{ Predictor } & \multirow[t]{2}{*}{ B } & \multirow[t]{2}{*}{ S.E. } & \multirow[t]{2}{*}{ Wald } & \multirow[t]{2}{*}{$\mathrm{df}$} & \multirow[t]{2}{*}{$p$-value } & \multirow[t]{2}{*}{ OR } & \multicolumn{2}{|c|}{$95 \% \mathrm{Cl}$ for OR } \\
\hline & & & & & & & Lower & Upper \\
\hline $\begin{array}{l}\text { Number of } \\
\text { Appointments }\end{array}$ & -.176 & .038 & 21.791 & 1 & $<.005^{*}$ & .839 & .779 & .903 \\
\hline Day of Week & .089 & .026 & 11.924 & 1 & $.001^{*}$ & 1.093 & 1.039 & 1.149 \\
\hline Postal Code 2480 & .131 & .043 & 9.469 & 1 & $.002 *$ & 1.140 & 1.049 & 1.239 \\
\hline Sex & .061 & .026 & 5.632 & 1 & .018 & 1.063 & 1.011 & 1.119 \\
\hline Age & -.015 & .001 & 532.156 & 1 & $<.005^{*}$ & .985 & .984 & .986 \\
\hline Aboriginal & 1.101 & .028 & 1583.077 & 1 & $<.005^{*}$ & 3.007 & 2.848 & 3.174 \\
\hline Constant & -2.427 & .056 & 1848.871 & 1 & .000 & .088 & & \\
\hline
\end{tabular}

$\mathrm{OR}=$ odds ratio; $\mathrm{B}=$ logistic regression coefficient; $\mathrm{S}$.E.= standard error of $\mathrm{B} ;$ Wald $=$ Wald test statistic; $\mathrm{df}=$ degrees of freedom; $\mathrm{p}=$ probability; ${ }^{*} p<0.01$

Table 2. Means and standard deviations of age in years by sex and Aboriginality in $n=8,544$ clients, who scheduled an appointment at a primary care clinic between 2011-2013

\begin{tabular}{|c|l|l|l|l|}
\hline \multirow{2}{*}{ Group } & \multicolumn{1}{|c|}{ Sex } & \multicolumn{1}{|c|}{ Mean Age } & \multicolumn{1}{|c|}{$\begin{array}{c}\text { Standard } \\
\text { Deviation }\end{array}$} & \multicolumn{1}{|c|}{ Number } \\
\hline \multirow{3}{*}{ Non-Aboriginal } & Male & 36.43 & 21.174 & 3,206 \\
\cline { 2 - 5 } & Female & 34.93 & 20.006 & 3,434 \\
\cline { 2 - 5 } & Total & 35.65 & 20.590 & 6,640 \\
\hline \multirow{3}{*}{ Aboriginal } & Male & 23.31 & 18.192 & 960 \\
\cline { 2 - 5 } & Female & 24.88 & 17.693 & 944 \\
\cline { 2 - 5 } & Total & 24.09 & 17.959 & 1,904 \\
\hline \multirow{3}{*}{ Total } & Male & 33.41 & 21.255 & 4,166 \\
\cline { 2 - 5 } & Female & 32.76 & 19.961 & 4,378 \\
\cline { 2 - 5 } & Total & 33.08 & 20.603 & 8,544 \\
\hline
\end{tabular}


Table 3. Multivariate logistical regression model predicting likelihood of FTA occurrence per person ( $n=8,561)$ between 2011-2013 at community medical centre, by children and young people under 18 years $(n=13,731)$ and adults $(n=77,016)$

\begin{tabular}{|c|c|c|c|c|c|c|c|c|c|}
\hline \multirow[t]{2}{*}{ Group } & \multirow[t]{2}{*}{ Predictor } & \multirow[t]{2}{*}{ B } & \multirow[t]{2}{*}{ S.E. } & \multirow[t]{2}{*}{ Wald } & \multirow[t]{2}{*}{$d f$} & \multirow[t]{2}{*}{$p$-value } & \multirow[t]{2}{*}{ OR } & \multicolumn{2}{|c|}{$95 \% \mathrm{Cl}$ for OR } \\
\hline & & & & & & & & Lower & Upper \\
\hline \multirow{6}{*}{ Adults } & $\begin{array}{l}\text { Number of } \\
\text { Appointments }\end{array}$ & .050 & .002 & 449.255 & 1 & .000 & 1.051 & 1.046 & 1.056 \\
\hline & Age & -.027 & .002 & 172.814 & 1 & $.000 *$ & .974 & .970 & .978 \\
\hline & Sex & -.019 & .066 & .086 & 1 & .769 & .981 & .862 & 1.116 \\
\hline & Aboriginal & 1.392 & .107 & 170.701 & 1 & $.000 *$ & 4.022 & 3.264 & 4.956 \\
\hline & $\begin{array}{l}\text { Female* } \\
\text { Aboriginal }\end{array}$ & .241 & .150 & 2.590 & 1 & .108 & 1.272 & .949 & 1.705 \\
\hline & Constant & -.508 & .090 & 31.780 & 1 & .000 & .602 & & \\
\hline \multirow{6}{*}{$\begin{array}{l}\text { Children } \\
\text { and } \\
\text { young } \\
\text { people }\end{array}$} & $\begin{array}{l}\text { Number of } \\
\text { Appointments }\end{array}$ & .129 & .010 & 181.783 & 1 & .000 & 1.138 & 1.117 & 1.159 \\
\hline & Age & .004 & .010 & .166 & 1 & .683 & 1.004 & .984 & 1.024 \\
\hline & Sex & .054 & .144 & .143 & 1 & .705 & 1.056 & .797 & 1.399 \\
\hline & Aboriginal & 1.071 & .145 & 54.361 & 1 & $.000 *$ & 2.917 & 2.195 & 3.878 \\
\hline & $\begin{array}{l}\text { Female* } \\
\text { Aboriginal }\end{array}$ & -.125 & .210 & .354 & 1 & .552 & .882 & .584 & 1.333 \\
\hline & Constant & -2.086 & .142 & 216.627 & 1 & .000 & .124 & & \\
\hline
\end{tabular}

$\mathrm{OR}=$ odds ratio; $\mathrm{B}=$ logistic regression coefficient; S.E.= standard error of $\mathrm{B} ;$ Wald = Wald test statistic; $\mathrm{df}=\mathrm{deg}$ rees of freedom; $\mathrm{p}=$ probability; ${ }^{*} p<0.01$ 
Table 4. Multivariate logistical regression model predicting likelihood of FTA occurrence per scheduled appointment ( $n=90,758$ appointments between 2011-2013 at community medical centre), demonstrating that the addition of the interaction term Aboriginal*Female significantly reduced the predictive effect size of sex in the full model.

\begin{tabular}{|c|c|c|c|c|c|c|c|c|}
\hline \multirow{2}{*}{ Predictor } & \multirow[t]{2}{*}{ B } & \multirow[t]{2}{*}{ S.E. } & \multirow[t]{2}{*}{ Wald } & \multirow[t]{2}{*}{ df } & \multirow[t]{2}{*}{$p$-value } & \multirow[t]{2}{*}{ OR } & \multicolumn{2}{|c|}{$95 \% \mathrm{Cl}$ for OR } \\
\hline & & & & & & & Lower & Upper \\
\hline $\begin{array}{l}\text { Number of } \\
\text { Appointments }\end{array}$ & -.175 & .038 & 21.610 & 1 & $<.005^{*}$ & .839 & .780 & .904 \\
\hline $\begin{array}{l}\text { Day of } \\
\text { Week }\end{array}$ & .088 & .026 & 11.777 & 1 & $.001^{*}$ & 1.092 & 1.039 & 1.149 \\
\hline \begin{tabular}{|l|} 
Postal Code \\
2480 [Should \\
the number \\
appear in Table \\
1, too?yes \\
done]
\end{tabular} & .130 & .043 & 9.244 & 1 & $.002 *$ & 1.138 & 1.047 & 1.237 \\
\hline Sex & .021 & .037 & .329 & 1 & .566 & 1.022 & .950 & 1.099 \\
\hline Age & -.015 & .001 & 534.011 & 1 & $<.005^{*}$ & .985 & .984 & .986 \\
\hline Aboriginal & 1.058 & .040 & 697.125 & 1 & $<.005^{*}$ & 2.880 & 2.662 & 3.115 \\
\hline $\begin{array}{l}\text { Aboriginal* } \\
\text { Female }\end{array}$ & .077 & .052 & 2.211 & 1 & .137 & 1.080 & .976 & 1.195 \\
\hline Constant & -2.402 & .059 & 1668.068 & 1 & .000 & .091 & & \\
\hline
\end{tabular}

OR = odds ratio; $B=$ logistic regression coefficient; S.E.= standard error of $B ;$ Wald = Wald test statistic; $d f=d e g r e e s$ of freedom; $\mathrm{p}=$ probability; ${ }^{*} p<0.01$ 